\title{
Fish behavior and fish guidance at hydropower intake screens for fish downstream passage
}

\author{
Franz Geiger ${ }^{1, *}$, Mathilde Cuchet $^{2}$, and Peter Rutschmann ${ }^{1}$ \\ ${ }^{1}$ Institute of Hydraulics and Water Resources Engineering, Department for Civil, Geo and \\ Environmental Engineering, Technical University of Munich, 82432 Walchensee, Bavaria, Germany \\ ${ }^{2}$ Ecohydraulic Consulting Cuchet, 82499 Wallgau, Bavaria, Germany
}

\begin{abstract}
Fish behaviour investigations under controlled laboratory conditions but nature like environment were conducted to clarify the efficiency of inclined and horizontal screen planes for fish protection and fish downstream passage at hydropower plants concerning different potamodromous species and various sizes. The dependency on the underlying geometric and hydraulic parameters was investigated and comprehensive models were deduced to describe these relations. Adequate geometric and hydraulic design could achieve high levels of fish protection and downstream passage efficiency, even for small fish, weak swimmers and riverbed/bottom oriented species. The results imply good transferability and accordance with field observations at large scale facilities and can provide valuable information for facility design.
\end{abstract}

\section{Fish downstream passage at hydropower plants}

Face to fish mortality during turbine passage at hydropower plants, fish protection and safe downstream passage techniques are required to achieve ecological compatibility at numerous facilities [1]. Mechanical barriers, i.e. screens with small bar clearance and low approach flow velocities, in combination with adequate bypass systems, can in principle prevent fish of respective size from turbine passage and provide secure downstream passage [2]. The major challenge of fish downstream passage remains the findability of the bypass entrance for migrating and drifting fish. Therefore, an inclined arrangement of flow direction and screen surface is meant to guide fish towards a bypass entrance at the downstream end of the screen [3].

Two basic approaches can be found for the implementation of guiding effects [4]. A vertical screen plane, inclined to the main flow direction, can guide fish towards a lateral bypass at the downstream end of the screen [5]. Such arrangements can provoke behavioural pattern of the fish, which result in guidance towards the bypass entrance $[6,7]$. Similarly, an inclined screen plane can guide fish towards a surface bypass [8]. While rather steep setups failed to achieve relevant guidance, but resulted in unfavourable fish damage at the screen [9], some arrangements with flat inclinations yielded remarkable guidance efficiency for salmons and eel $[10,11]$. General relations of the efficiency as well

\footnotetext{
* Corresponding author: franz.geiger@tum.de
} 
as the suitability of such concepts for numerous potamodromous fish species remained so far unresolved, despite their ecological relevance [12].

An alternative, horizontal screen arrangement is proposed by the TUM Hydro Shaft Power Plant concept [13]. A completely submerged horizontal screen plane is installed upstream of a weir. It is flush with the river bed and receives approach flow from three sidelines, while the fourth sideline is aligned with the weir and joins a gate. An opening in this gate provides direct outflow to a tailwater cushion and thus possible fish downstream passage. Figure 1 provides an exemplary setup. The flow distribution in the intake area suggests three-dimensional guiding effects towards the gate center area with favourable inclinations of local flow direction and screen plane in most areas, as also illustrated in figure 1 by 3D-ADV measurement results at a respective physical model test [14].
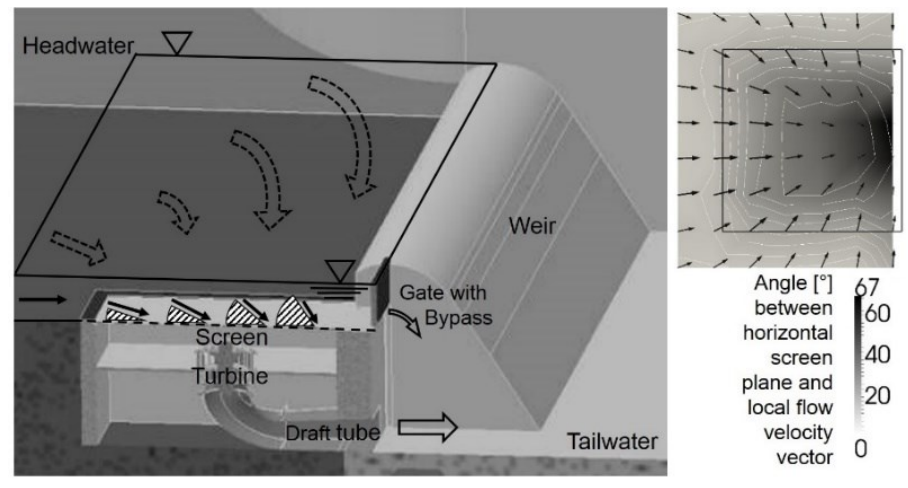

Fig. 1. Exemplary visualization of the Hydro Shaft concept with illustration of flow directions in the headwater and above the screen (left) and plan view of exemplary flow velocity distribution above the screen, where arrows represent horizontal flow velocity components, isolines provide vertical velocity development, greyscale shows inclination of local flow velocity and screen plane, black rectangle represents the screen outline (right), main flow direction for both images from the left to the right

The present work is based on three experimental campaigns concerning the fish behaviour face to inclined and horizontal screens. The actual efficiency of such concepts and their dependency on the underlying geometric and hydraulic parameters, i.e. screen inclination, bar clearance and approach flow velocity were investigated for different fish species and sizes. In particular, a number of potamodromous species of limited body size and swimming capacity or specific comportment were accounted for, due to their ecological relevance and potential endangerment. Individual details for the single test series can be found in the respective test reports and [15].

\section{Material and Method}

\subsection{Test setups and variations}

The test setups were integrated into the open-air channel system of the hydraulic laboratory of the Technical University of Munich (TUM) in Obernach. It allows for gauge flume controlled water supply with up to $2 \mathrm{~m}^{3} / \mathrm{s}$ from the Isar-River and variation of water surface elevations by tailwater gates. The facility enables relatively large scale tests under controlled laboratory conditions but nature like environmental conditions at a time. Table 1 summarizes the geometric and hydraulic parameter variations. The hydraulic situation at the screens and bypasses were recorded by 3D-Acoustic Doppler Velocimetry (Nortek). 
The investigations of inclined screens were conducted in a channel reach with $1.2 \mathrm{~m}$ width and $2 \mathrm{~m}$ height. Figure 2 illustrates the test setup. It allowed for variation of the screen inclination, the bar clearance and the bypass geometry. The homogeneous, horizontal approach flow velocity was set to $0.5 \mathrm{~m} / \mathrm{s}$. A bypass entrance opening with $61 \mathrm{~cm}$ width and $27 \mathrm{~cm}$ water depth was located at the downstream end of the screen. PIT antennas were mounted at the bypass entrance and downstream the screen, in order to detect bypass and screen passage of tagged fish. A window in the channel wall with observation chamber provided optical access to screen and bypass.

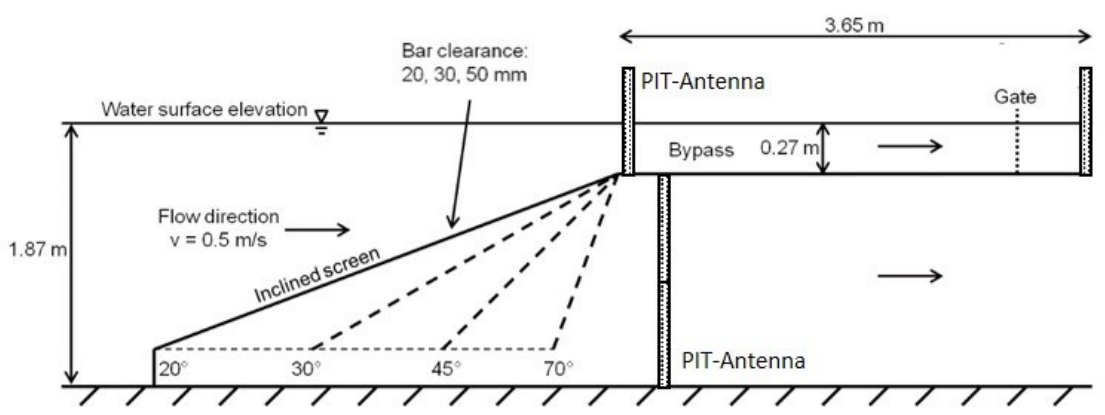

Fig. 2. Schematic longitudinal section for inclined screen experimental setup, test section width $1.2 \mathrm{~m}$, bypass entrance width $61 \mathrm{~cm}$, main flow direction from the left to the right

The behaviour investigations for horizontal screens were conducted in a $10.1 \mathrm{~m}$ wide test section with two subsequent setups. At first, the behaviour of large fish (no screen passage possible) was accounted for with a simplified setup, which produced the hydraulic conditions at a horizontal screen with $17.5 \mathrm{~mm}$ bar clearance, $2.6 \mathrm{~m}$ length and $2.4 \mathrm{~m}$ width. For the later investigation of small fish (screen passage physically possible) the setup was completed to a fully functional hydropower plant with a $35 \mathrm{~kW}$ Kaplan turbine (750 $\mathrm{mm}$ runner diameter, $1.5 \mathrm{~m}^{3} / \mathrm{s}$ design discharge at $2.5 \mathrm{~m}$ head). The screen featured 20 $\mathrm{mm}$ bar clearance, $2 \mathrm{~m}$ length and $2 \mathrm{~m}$ width. The double regulated turbine (control device and runner blades) enabled the investigation of different screen discharges, i.e. screen approach flow velocities. Figure 3 shows a longitudinal section of the $35 \mathrm{~kW}$ test setup.

For both setups with horizontal screen, two alternative bypass openings were tested, one surface near and one bottom near. Each opening provided a $30 \mathrm{~cm}$ wide and $25 \mathrm{~cm}$ high outflow to the tailwater cushion of $90 \mathrm{~cm}$ height. Nets and perforated metal plates $(4 \mathrm{~mm}$ aperture) were installed in the test section at the headwater upstream cross section, in a cross section between bypass tailwater and draft tube exist and at the tailwater downstream cross section to identify all fish passages by complete fishing of all areas after each test.

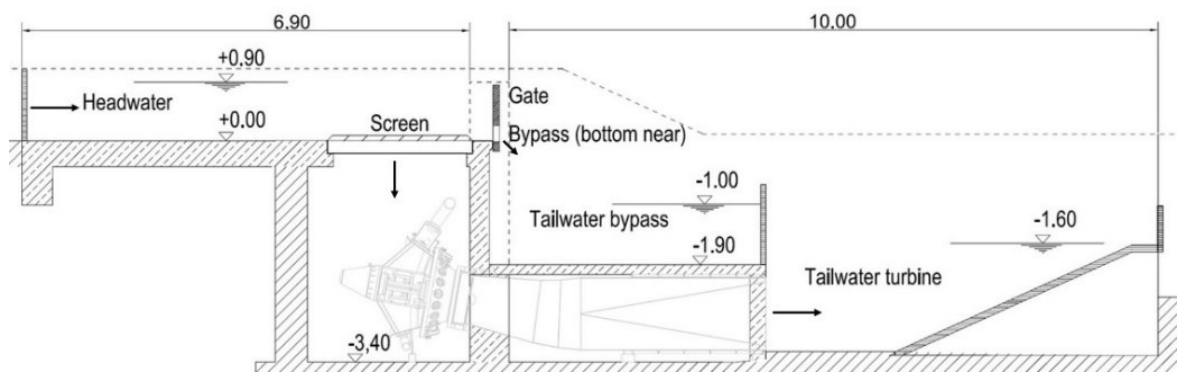

Fig. 3. Longitudinal sections of the $35 \mathrm{~kW}$ test facility with horizontal screen arrangement, headwater width $10.1 \mathrm{~m}$, screen surface $2.0 \mathrm{~m}$ x $2.0 \mathrm{~m}$, main flow direction from the left to the right 
Table 1. Basic geometric and hydraulic parameters and their variations for all test series

\begin{tabular}{|c|c|c|c|c|}
\hline Test series & Bypass position & $\begin{array}{c}\text { Bar clearance } \\
{[\mathrm{mm}]}\end{array}$ & $\begin{array}{c}\text { Screen } \\
\text { inclination }\left[{ }^{\circ}\right]\end{array}$ & $\begin{array}{c}\text { Approach flow } \\
\text { velocity }[\mathrm{m} / \mathrm{s}]\end{array}$ \\
\hline$\# 1$ & surface & $20,30,50$ & $20,30,45,70$ & 0.5 \\
\hline$\# 2$ & surface, bottom & 17.5 & 0 (horizontal) & 0.4 \\
\hline$\# 3$ & surface, bottom & 20 & 0 (horizontal) & $0.3,0.4,0.5$ \\
\hline
\end{tabular}

The employed fish were deduced from river sites by electrofishing as far as possible. For some species farm fish had to be deployed. Table 2 provides the employed fish species, sizes and origins. The fish were transferred to the test site in aerated transport containers and stocked in circular flow tanks with water supply from the tests sections. At least $48 \mathrm{~h}$ of recovery and adaption to water conditions were provided for all fish. A veterinary investigation of the fish assured good and representative health conditions. As far as possible and especially for all fish inserted in test series \# 3, fish were only employed for one time, to avoid cumulative stress and learning effects.

Table 2. Investigated fish species, sizes and origins, case numbers and tracking methods

\begin{tabular}{|c|c|c|c|c|c|}
\hline $\begin{array}{c}\text { Test } \\
\text { series }\end{array}$ & Species & $\begin{array}{c}\text { Inserted } \\
\text { fish }\end{array}$ & $\begin{array}{c}\text { Fish length } \\
{[\mathrm{mm}]}\end{array}$ & $\begin{array}{c}\text { Fish } \\
\text { origin }\end{array}$ & $\begin{array}{c}\text { Passage } \\
\text { tracking method }\end{array}$ \\
\hline$\# 1$ & Barbel (Barbus barbus) & 600 & $190-610$ & wild & PIT tagging \\
\hline$\# 1$ & Chub (Squalius cephalus) & 600 & $195-465$ & wild & PIT tagging \\
\hline$\# 1$ & Nase (Chondrostoma nasus) & 600 & $200-505$ & wild & PIT tagging \\
\hline$\# 2$ & Brown trout (Salmo trutta) & 90 & $190-500$ & farm & spatial separation \\
\hline$\# 2$ & Barbel (Barbus barbus) & 96 & $180-640$ & wild & spatial separation \\
\hline$\# 2$ & Chub (Squalius cephalus) & 162 & $130-490$ & wild & spatial separation \\
\hline$\# 3$ & Brown trout (Salmo trutta) & 818 & $70-220$ & wild & spatial separation \\
\hline$\# 3$ & Grayling (Thymallus thymallus) & 776 & $50-215$ & farm & spatial separation \\
\hline$\# 3$ & Barbel (Barbus barbus) & 64 & $44-200$ & wild & spatial separation \\
\hline$\# 3$ & Minnow (Phoxinus phoxinus) & 49 & $50-80$ & farm & spatial separation \\
\hline$\# 3$ & Bullhead (Cottus gobio) & 267 & $45-125$ & wild & spatial separation \\
\hline
\end{tabular}

\subsection{Test procedure}

After establishing the desired hydraulic conditions, a set of fish was smoothly inserted into the headwater area with a specialized insertion vessel. Subsequently, the fish could move freely and undisturbed for a test duration of $24 \mathrm{~h}$ while hydraulic and geometric conditions maintained constant. During the tests, fish behaviour at the screen and at the bypass entrance was recorded by under water video devices and abiotic parameters were logged 
(temperature, oxygen content, $\mathrm{pH}$-value, conductibility, light intensity). For test series with inclined screen all PIT signals were recorded.

After the test duration, further fish passage was disabled and all fish were retrieved from the test section. Fish length and condition were recorded and the fish were observed in circular flow tanks for $96 \mathrm{~h}$ to account for potential long-term damage of turbine passage. All work with live fish was conducted in accordance to animal welfare regulations and the specific bioassay permissions.

\section{Results and Discussion}

\subsection{General fish behaviour}

During the test series the fish showed frequent activity and fish of all employed species and sizes effectively passed through all investigated bypass openings. The video footage, PITAntenna signals and fishing results were analysed with regard to general and species specific characteristics. A number of representative aspects for natural fish behaviour could be confirmed. Typical pattern with regard to daylight influence on activity (day / night), social behaviour (single / swarm) and swimming horizon (surface / ground) were observed. Statistical regression analysis revealed significant positive relation between natural water temperature variation and the fish activity throughout the time of day. The general behaviour aspects were no focus of the experimental campaign, but demonstrate a rather natural and undisturbed fish behaviour and thus indicate good transferability of results to river sites.

\subsection{Fish behaviour at the screen}

For all test series, the fish showed positive rheotaxis. They could move freely in the whole headwater area. No exceedance of swimming capacity or impingement at the screen were observed, but serious injury occurred at certain arrangements of inclined screens due to screen contact or passage. Figure 4 provides exemplary fish swimming comportment.

At the inclined screens, the fish slowly drifted towards the screen, aligned with the flow velocity. Just before or at beginning contact of the caudal fin with the screen bars, the fish increased their swimming speed and the distance from the screen. This was associated with a shift of the fish axis to an angle between the horizontal flow velocity and the screen perpendicular axis. The value of this orientation in relation to the horizontal increased for steeper screen inclinations. Once the fish obtained a distance from the screen in the magnitude of the fish length, he restarted drifting in flow aligned orientation. This process effectively entailed a fish movement along the screen, towards the surface bypass. It is coherent with common models for vertical screens inclined against the flow direction [6].

However, the guidance process was frequently interrupted and aborted with subsequent withdrawal to the headwater. Beside social interaction, this was mostly caused by events of serious screen contact, i.e. when the caudal fin got between screen bars. For steep inclinations, the whole fin got trapped between the bars and affected the swimming capability. High physical efforts and injury risks were associated with escape. For low inclined screens, such events only affected the ventral tip of the caudal fin with minor interference on swimming capability, which was favourable for the development of the iterative guidance process towards the screen. Moreover, for large bar clearance fish frequently tried to actively pass through the bars, facing serious scale loss and skin wounds.

For the horizontal screen, the detailed analysis of swimming orientation had to account for the complex three dimensional flow velocity distribution. In general, the fish showed 
positive rheotaxis and rather continuous drift along the screen surface, than iterative movement pattern. This comportment is in continuance with the above results for inclined screens, face to the small inclinations between local flow direction and screen pane in combination with the small approach flow velocities. Similar systematics for improved guidance were found for quantitative passage considerations.
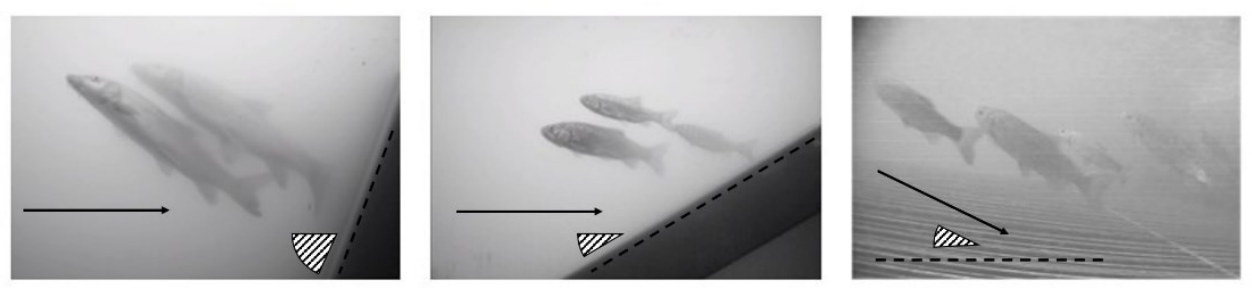

Fig. 4. Fish behaviour at the screen for $70^{\circ}$ screen inclination (left), $30^{\circ}$ inclination (middle) and horizontal screen (right), with illustration of respective flow directions (arrows), screen orientations (dashed lines) and resulting inclinations (sectors), main flow direction from the left to the right

\subsection{Fish guidance considerations}

When considering large fish, i.e. fish that cannot travers the screen, the guidance efficiency can be characterized by the number of fish which passed to the tailwater in relation to the introduced fish ("passage rate"). Relative statements are focussed on, since absolute values depend for example on the test duration and cannot be transferred. With regard to small fish, i.e. fish which can physically travers the screen, the partition of fish which passed through the bypass in relation to all fish which passed to the tailwater (bypass and screen/turbine) can be considered ("bypass passage partition").

For both parameters, the whole range of the respective values could be observed (passage rate: $10-90 \%$, bypass passage partition: $0-100 \%$ ). Regression analysis were conducted, to deduce relevant relations ( $\mathrm{R}$ 3.1.1). In general, the actual values depended on the given species and showed significant increase $(\mathrm{p}<0.05)$ with increasing fish length. For inclined screens, the guidance efficiency increased significantly with decreasing bar clearance and with flatter screen inclination. The discharge variation at horizontal screens provided significant increase of guidance efficiency with decreasing approach flow velocities. The bottom near bypass opening achieved better guidance for all employed species and sizes in comparison to surface arrangement. The general relations are coherent with the common model assumptions for fish guidance [6] while the relations provide furthermore systematic quantification of the guidance efficiency. The detailed figures for each parameter combination can be found in the respective test reports and [15].

For comprehensive analysis of the guidance efficiency relationships, the observed values were subjected to logistic regression ( $\mathrm{R}$ 3.1.1) for several species. The obtained statistical modelling of the generalized guidance efficiency shows for example, that screen passage partitions cannot be predicted by the ratio of fish length and bar clearance. Values for $10 \mathrm{~cm}$ long barbel at $20 \mathrm{~mm}$ screens differ from those of $15 \mathrm{~cm}$ barbel at $30 \mathrm{~mm}$ screens of same inclination and approach flow velocity, as the swimming capacity influences the guidance efficiency and depends on the fish length.

Exemplary modelling of bypass passage partitions are illustrated in figure 5 for different screen arrangements with $20 \mathrm{~mm}$ bar clearance. The models demonstrate coherent trends for increasing guidance efficiency with flatter screen inclination and with decreasing approach flow velocity. The graphic also features two reference values at larger facility setups $[9,11]$. The observed values show accordance with the corresponding model 
predictions. Nevertheless, the comparability and transferability of the models has to be considered carefully for practical application.
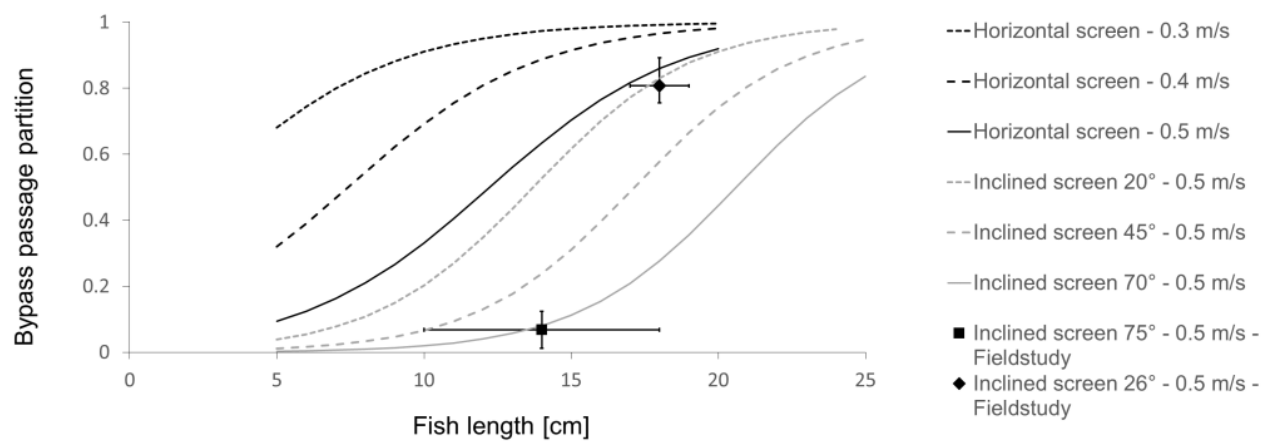

Fig. 5. Modelling results for bypass passage partitions at $20 \mathrm{~mm}$ screens in dependency of fish length, screen inclination and approach flow velocity and comparison to field observations at respective facilities $[9,11]$ error bars indicate the respective spread and uncertainty of the available data

The present studies also accounted for a number of fish species with particular ground bound swimming behaviour or relatively limited body size and swimming capacity. The results demonstrate that the investigated setups can also achieve respectable efficiency for such species. $43 \%$ of the fish which passed through the surface bypass of the inclined screen were barbel. For the horizontal screen in test series \# 2 barbel showed higher passage rates than brown trout and chub of respective size. In the given test duration an average of $67 \%$ of barbel with $180-250 \mathrm{~mm}$ body length and $95 \%$ of those with $400-$ $640 \mathrm{~mm}$ length passed to the tailwater. Bypass passage partitions at horizontal screens observed in test series \# 3 are summarized in table 3 for respective species. For almost all cases, the majority of fish passed through the bypass.

Table 3. Bypass passage partitions for particular fish species in test series \# 3 with bottom bypass

\begin{tabular}{|c|c|c|c|}
\hline Species & Fish length & Approach flow velocity & Bypass passage partition \\
\hline Barbel & $45-200 \mathrm{~mm}$ range & $0.5 \mathrm{~m} / \mathrm{s}$ & $44-83 \%$ \\
\hline Minnow & $59 \mathrm{~mm}$ average & $0.5 \mathrm{~m} / \mathrm{s}$ & $65 \%$ \\
\hline Bullhead & $81 \mathrm{~mm}$ average & $0.3-0.5 \mathrm{~m} / \mathrm{s}$ & $59-82 \%$ \\
\hline
\end{tabular}

\section{Conclusions}

The conducted fish behaviour investigations could elucidate the suitability and efficiency of fish protection and fish downstream passage at inclined and horizontal screens with respectable bypass systems. The results indicate good transferability to natural sites. Flat inclined screens $\left(\leq 45^{\circ}\right)$ with small bar clearance $(\leq 20 \mathrm{~mm})$, adequate approach flow velocity (here $0.5 \mathrm{~m} / \mathrm{s}$ ) and appropriate surface bypass could achieve efficient fish protection and downstream passage, even for bottom oriented fish like barbel. The horizontal screen arrangement with bottom near bypass opening further improved fish 
downstream passage conditions and provided safe passage even for major partitions of minnow and bullhead. An adaption of bar clearance and approach flow velocity enables further ecological improvement potential, if required.

Adequate geometric and hydraulic conditions, achieve partial fish protection and downstream guidance even for fish smaller than the bar clearance, where the screen does not serve as physical, but as behavioural barrier. At the same time, the studies are coherent with field observations [9], showing that inappropriate arrangements can entail relevant fish damage at the screen and effectively do more harm than good. The efficiency depends largely on behaviour based guiding effects, which require positive interaction of screen and bypass setup as well as flow conditions. The obtained data can provides valuable quantitative orientation for facility design and assessment, although transferability has to be considered individually in regard of the specific setup and conditions.

\section{Acknowledgements}

Parts of the presented studies have been funded by the Grenzkraftwerke GmbH, the German federal Ministry of Economic Affairs and Energy (BMWi) and the Bavarian State Ministry of the Environment and Consumer Protection (StMUV). Partially, they were supported by Eberstaller Zauner Büros (EZB), the Bavarian Environment Agency (LfU) Unit Fish and Freshwater Ecology, the Bavarian State Research Center for Agriculture (LfL) - Institute for Fisheries and the fishery consultant of the district of Schwaben. The Muhr GmbH provided the steel hydraulics constructions for the $35 \mathrm{~kW}$ facility.

\section{References}

1. M. Larinier, J. Dartiguelongue, Bull. Fr. Pêche Piscic, 312/313: 1-90 (1989)

2. M. Larinier., F. Travade, Bull. Fr. Pêche Piscic, 364 suppl.: 181-207 (2002)

3. D. Hefti BAFU Umwelt-Wissen Nr. 1210: 79 S. (2012)

4. DWA, ISBN: 978-3-937758-88-6 (2006)

5. F. Travade, M. Larinier, S. Subra, P. Gomes, E. De-Oliveira, Knowl. Managt. Aquatic Ecosyst. 398 (2010)

6. D. S. Pavlov, FAO Fisheries Technical Paper 308, ISBN 92-5-102857-5 (1989)

7. A. W. H. Turnpenny, N. O’Keeffe, Environment Agency, SC030231 (2005)

8. D. Courret, M. Larinier, Agence De l'Environment et de la Maitrise de l'Energie (2008)

9. J. Schneider, D. Hübner, E. Korte, BFS, Endbericht Kostheim (2012)

10. O. Calles, S. Karlsson, P. Vezza, C. Comoglio, and J. Tielman, Freshwater Biology 58.10, pp. 2168-2179. ISSN: 1365-2427 (2013)

11. S. Tomanova, D. Courret, A. Alric, SHF-HydroES-Conference (2016)

12. M. Larinier, FAO Fisheries Technical Paper 419, Rome, ISBN 92-5-104694-8 (2001)

13. P. Rutschmann, A. Sepp, F. Geiger, J. Barbier, International Water Power \& Dam Construction, 63, 22-25. (2011)

14. F. Geiger, A. Sepp, P. Rutschmann, Korrespondenz Wasserwirtschaft, Vol. 9, Nr. 10, S. 627-632 (2016)

15. M. Cuchet, $\mathrm{PhD}$ Thesis «Fish protection and Downstream Migration at Hydropower Intakes, Technical University of Munich, ISBN: 978-3-943683-08-0 (2014) 